\title{
The differential effects of additional cortical lesions in rats with single- or multiple-stage lesions of the visual cortex
}

\author{
S. W. SCHEFF, D. C. WRIGHT, W. K. MORGAN, and R. P. BOWERS \\ Department of Psychology and Dalton Research Center, University of Missouri, Columbia, Missouri 65201
}

\begin{abstract}
Male albino rats relearned a black-white discrimination for food after posterior neocortex was bilaterally removed in a single operation ("single stage") or in two unilateral operations ("multiple stage"). Single-stage animals showed no savings in relearning (relearning errors = learning errors). Multiple-stage animals showed positive savings (relearning errors < learning errors). To assess cortical reorganization, the rats were given additional lesions and again retrained. Cortex either contiguous or noncontiguous with the posterior lesion was removed bilaterally. Contiguous and noncontiguous lesions produced different effects only among animals with prior multiple-stage posterior lesions. Rats with single-stage posterior lesions and contiguous or noncontiguous lesions showed positive savings and did not differ from each other or from rats with multiple-stage posterior and noncontiguous lesions. Rats with multiple-stage posterior and contiguous lesions made more errors and showed negative savings. The role of contiguous cortex in the serial lesion effect was also tested with two additional groups. Rats given noncontiguous cortex lesions prior to multiple-stage posterior lesions showed positive savings in retraining. Rats given contiguous cortex lesions prior to multiple-stage posterior lesions showed negative savings.
\end{abstract}

Following bilateral removal of the visual cortex in a single operation, rats can relearn a brightness discrimination, but relearning requires as many trials as did original learning (Lashley, 1920, 1922, 1926, $1929,1930)$. That is, rats with single-stage bilateral lesions of the visual cortex (SS) show no savings from original learning. Following multiple-stage bilateral lesions of the visual cortex (MS), rats show no savings in relearning if no training is given in the interval between the two unilateral lesions, but show positive savings if training is given during the interoperative interval (IOI) (Glendenning, 1972; Kircher, Braun, Meyer, \& Meyer, 1970; Petrinovich \& Carew, 1969; Scheff \& Wright, 1977; Thompson, 1960).

In a pattern discrimination task, MS rats given training on the task (Spear \& Barbas, 1975) and MS rats allowed to freely explore a patterned visual environment (Dru, Walker, \& Walker, 1975) during the IOI can reacquire the pattern discrimination, while MS animals given no light, diffuse light, or passive exposure to pattern vision during the IOI cannot reacquire the pattern discrimination (Dru et al., 1975). Animals given SS lesions of the visual cortex cannot learn or relearn a pattern discrimination (Horel, Bettinger, Royce, \& Meyer, 1966; Lashley, 1929; Spear \& Barbas, 1975).

Supported in part by the John M. Dalton Research Center, University of Missour, Columbia, Missouri 65201. S. W. Scheff is now at the Department of Psychobiology, University of California, Irvine, California 92717.
In short, the visual discrimination learning and/or relearning of MS animals with relevant experience during the IOI is both quantitatively and qualitatively different from that of SS animals.

Interpretations of reorganization/recovery of function following visual cortex lesions typically stress subcortical mechanisms (Cooper, Blochert, Gillespie, \& Miller, 1972; Horel et al., 1966; Lashley, 1935). While this interpretation may be accurate for SS animals, reorganization of function may occur cortically in MS animals given training during the IOI. Indeed, if cortical mechanisms are necessary to the performance of pattern discriminations, then the results of Dru et al., (1975) and Spear and Barbas (1975) can only be explained by arguing that cortical reorganization occurs in MS animals given appropriate IOI experience.

In this experiment, the role of cortical reorganization is examined by exploring the effects of singleand multiple-stage lesions of the visual cortex [Krieg's (1946) areas: 17, 18, 18a] given in conjunction with bilateral removal of cortex either contiguous (C) or noncontiguous (NC) with the visual cortex lesion site. It was hypothesized that if cortical reorganization is important for the serial lesion effect, then contiguous, "extrastriate" cortex is the most likely site of this reorganization, and that cortical reorganization is relatively unimportant in SS animals. Thus, lesions of either C or NC cortex should exert "massaction" effects for SS animals that are equivalent to each other and equivalent to the effects of NC lesions in MS animals, while $\mathrm{C}$ lesions in MS animals 
should have devastating consequences that eliminate any serial lesion effect.

\section{METHODS}

\section{Subjects}

Sixty-four Sprague-Dawley-derived, male albino rats (Holtzman, Madison, Wisconsin) were used. The animals were 60-75 days old at the start of the investigation and were housed singly in metal cages under a 12/12 h light-dark cycle. Water was available ad lib. Food (Purina Rat Chow) was restricted to two large pellets (average $8 \mathrm{~g} /$ pellet) per day, given immediately after testing.

\begin{abstract}
Apparatus
A T-maze with 12 -in.-high walls made of $3 / 4$-in. plywood was used. The startbox of the maze was 5 in. long and 4 in. wide; the arms were $19 \mathrm{in}$. long and 5 in. wide. An additional runway, 4 in. wide and 12 in. long, separated the startbox from the arms of the maze. A T-shaped opaque guillotine door separated the startbox from the arms of the maze and the arms from each other. A clear Plexiglas door separated the startbox from the opaque guillotine door.

Two pivotable pieces of galvanized steel, $1.6 \mathrm{~mm}$ in thickness, were mounted on the black wall of the maze arms such that either a white or a black painted surface could extend from the choice point to the offset goal area at the end of each arm. The stimulus plates were illuminated by $25-\mathrm{W}$ bulbs shining through the translucent Plexiglas front wall of each arm. The maze was cleaned after each animal was run. The interior of the maze was painted flat gray. Containers of wet mash (Purina Rat Chow and water) were placed in both goal areas to equate odor cues. The containers in the goal area at the end of the incorrect arm was covered with wire screen to prevent access to the mash.
\end{abstract}

\section{Procedure}

Three days before the start of training, the subjects were handled for $10 \mathrm{~min}$ each day, and were permitted to explore the maze with no reinforcement in either arm of the maze.

On Day 4, the training period began with five trials per day. On each trial, the animal was placed in the startbox, and, after $10 \mathrm{sec}$, the opaque guillotine door separating the runway from the arms of the maze was opened, permitting the animal to view the stimuli from behind the clear Plexiglas start door. Five seconds later, the start door was raised and the animal then had 2 min to choose one of the two arms. Following choice (animal's body completely in one arm), the clear Plexiglas door and the opaque guillotine door were closed and the animal remained in the chosen arm/goal area for $10 \mathrm{sec}$. Half of the animals were run to white correct and half were run to black correct. The right/left position of the correct arm varied according to a modified Gellerman (1933) sequence. The animals were given five noncorrection trials per day.

\section{Experimental Design}

Table 1 provides an outline of the training and surgical schedules. All subjects were first trained to a criterion of 14 out of 15 correct in three successive sessions, with 5 out of 5 correct on the last session. The subjects were matched on the basis of days to criterion on original training, and eight animals were assigned to each of the eight surgical groups. Within 4 days of original training, all subjects received the first operation. After the first operation, the animals were given 2 days of recovery, followed by 4 days of interoperative training which was identical in all respects to original learning. Following interoperative training, the rats were given 3 days of "preoperative recovery," with wet mash available ad lib., to allow dietary repletion prior to surgery, to aid recovery from surgical trauma. The second operation and 2 days of postoperative recovery were then given. The animals in Groups 1-6 (unoperated control, sham-operated control, $\mathrm{SS}+\mathrm{NC}, \mathrm{SS}+\mathrm{C}, \mathrm{MS}+\mathrm{NC}$, and $\mathrm{SM}+\mathrm{C}$ ) were then restrained to criterion following the procedures for original learning, while the animals in Groups 7 and 8 (NC+MS and C+MS) were given 4 days of interoperative training. After this training period (retrain-1 for Groups 1-6, interoperative training-2 for Groups 7 and 8), the animals were given 3 days of preoperative recovery, the third operation, and 2 days of postoperative recovery. All animals were then retrained to criterion (retrain-2 for Groups 1-6, retrain-1 for Groups 7 and 8), with procedures identical to those of original learning.

The surgical schedule outlined in Table 1 can be summarized as follows: Two control groups either underwent no surgical manipulations (Groups 1, Unop C) or received three sham operations (Group 2, Sham). Two groups with SS visual cortex lesions received sham operations in Operation 1 , bilateral visual cortex lesions in Operation 2, and bilateral lesions of cortex either noncontiguous (Group 3, SS + NC) or contiguous (Group 4, $\mathrm{SS}+\mathrm{C}$ ) with the visual cortex lesion site in Operation 3. Two groups with MS visual cortex lesions received unilateral visual cortex lesions in Operations 1 and 2 and bilateral noncontiguous (Group 5, MS + NC) or contiguous (Group 6, MS + C) cortex lesions in Operation 3. Two MS groups received unilateral visual cortex lesions in Operations 2 and 3 after having had bilateral noncontiguous (Group 7, NC+MS) or contiguous (Group 8, $\mathrm{C}+\mathrm{MS}$ cortex lesions in Operation 1.

\section{Surgical Procedure}

Lesions were made by aspiration under sodium pentobarbital anesthesia. Visual cortex (occipital) lesions encompassed the striate and peristriate cortex [Krieg's (1946) area 17, 18, 18a], and were made either in one or two stages, depending upon group designation. The contiguous cortex lesions and noncontiguous cortex lesions were approximately equal to each other in size and always entailed bilateral removal in a single operation. For lesion groups, burr holes were made over the designated area and enlarged with rongeurs. The dura was opened and the underlying neocortex aspirated. Gelfoam was placed in the area and neosporin was applied to the wound prior to suturing. For sham operations, the animal was anesthetized, a midline incision was made to expose the dorsal surface of the skull, and neosporin powder was applied before the wound was sutured. Unoperated controls were left in their home cages during the operation period, but were treated the same, pre- and postoperatively, as the subjects receiving operations.

\section{Histological Procedures}

For histological verification of the lesion, the brains were perfused in situ via the left ventricle of the heart with physiological saline and $10 \%$ buffered Formalin solution. The whole brains were photographed, and the photographic slides were projected onto Lashley diagrams and the extent of the lesions was traced. The whole brains were then sectioned on a freezing microtome at $30 \mu$, and every third section was saved through the lateral geniculate. The sections were stained with cresyl violet and mounted for microscopic examination.

\section{RESULTS}

\section{Anatomical}

Figure 1 indicates the representative cortical damage for $\mathrm{SS}+\mathrm{C}, \mathrm{SS}+\mathrm{NC}, \mathrm{MS}+\mathrm{C}, \mathrm{MS}+\mathrm{NC}$, $\mathrm{C}+\mathrm{MS}$, and $\mathrm{NC}+\mathrm{MS}$ lesions. Lesion extent, among all animals, included most of visual areas 17,18 , and 18a. Where sparing of the striate cortex was found, it was substantially confined to the caudal-medial portions of the cerebral hemispheres. The most 
Table 1

Summary of the Experimental Design

\begin{tabular}{|c|c|c|c|c|c|c|c|c|c|c|c|}
\hline & Group & $\begin{array}{l}\text { Original } \\
\text { Training }\end{array}$ & Operation 1 & & $\begin{array}{c}\text { Inter-op } \\
\text { Train-1 }\end{array}$ & & Operation 2 & & $\begin{array}{c}\text { Retrain-1 } \\
\text { (Groups 1-6) } \\
\text { or } \\
\text { Inter-op-2 } \\
\text { (Groups 7-8) }\end{array}$ & Operation 3 & $\begin{array}{c}\text { Retrain-2 } \\
\text { (Groups 1-6) } \\
\text { or } \\
\text { Retrain-1 } \\
\text { (Groups } 7-8 \text { ) }\end{array}$ \\
\hline 1 & Unop C & $\begin{array}{l}\text { Train to } \\
\text { Criterion }\end{array}$ & None & & $\begin{array}{l}4 \text { Days } \\
\text { Training }\end{array}$ & & None & & $\begin{array}{l}\text { Train to } \\
\text { Criterion }\end{array}$ & None & $\begin{array}{l}\text { Train to } \\
\text { Criterion }\end{array}$ \\
\hline 2 & Sham & $\begin{array}{l}\text { Train to } \\
\text { Criterion }\end{array}$ & Sham & & $\begin{array}{l}4 \text { Days } \\
\text { Training }\end{array}$ & & Sham & & $\begin{array}{l}\text { Train to } \\
\text { Criterion }\end{array}$ & Sham & $\begin{array}{l}\text { Train to } \\
\text { Criterion }\end{array}$ \\
\hline 3 & $\mathrm{SS}+\mathrm{NC}$ & $\begin{array}{l}\text { Train to } \\
\text { Criterion }\end{array}$ & Sham & $\stackrel{N}{\stackrel{d}{*}}$ & $\begin{array}{l}4 \text { Days } \\
\text { Training }\end{array}$ & $\underset{\substack{\infty \\
c}}{w}$ & $\begin{array}{l}\text { Bilateral } \\
\text { V Ctx }\end{array}$ & 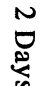 & $\begin{array}{l}\text { Train to }{ }^{\omega} \\
\text { Criterion }\end{array}$ & 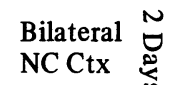 & $\begin{array}{l}\text { Train to } \\
\text { Criterion }\end{array}$ \\
\hline 4 & $\mathrm{SS}+\mathrm{C}$ & $\begin{array}{l}\text { Train to } \\
\text { Criterion }\end{array}$ & Sham & $\begin{array}{l}\infty \\
0 \\
0 \\
0 \\
1\end{array}$ & $\begin{array}{l}4 \text { Days } \\
\text { Training }\end{array}$ & To & $\begin{array}{l}\text { Bilateral } \\
\text { V Ctx }\end{array}$ & 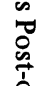 & $\begin{array}{ll}\text { Train to } & \text { To } \\
\text { Criterion } & 0 \\
0\end{array}$ & \begin{tabular}{ll} 
Bilateral & \multicolumn{1}{c}{} \\
C Ctx & $\stackrel{\infty}{1}$
\end{tabular} & $\begin{array}{l}\text { Train to } \\
\text { Criterion }\end{array}$ \\
\hline 5 & $\mathrm{MS}+\mathrm{NC}$ & $\begin{array}{l}\text { Train to } \\
\text { Criterion }\end{array}$ & $\begin{array}{l}\text { Unilateral } \\
\text { V Ctx }\end{array}$ & $\frac{i}{0}$ & $\begin{array}{l}4 \text { Days } \\
\text { Training }\end{array}$ & $\underset{0}{0}$ & $\begin{array}{l}\text { Unilateral } \\
\text { V Ctx }\end{array}$ & $\begin{array}{l}0 \\
0 \\
0\end{array}$ & $\begin{array}{l}\text { Train to } \\
\text { Criterion }\end{array}$ & 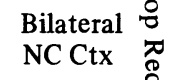 & $\begin{array}{l}\text { Train to } \\
\text { Criterion }\end{array}$ \\
\hline 6 & $\mathrm{MS}+\mathrm{C}$ & $\begin{array}{l}\text { Train to } \\
\text { Criterion }\end{array}$ & $\begin{array}{l}\text { Unilateral } \\
\text { V Ctx }\end{array}$ & $\stackrel{8}{\$}$ & $\begin{array}{l}4 \text { Days } \\
\text { Training }\end{array}$ & $\underset{*}{\stackrel{\varrho}{\rightleftarrows}}$ & $\begin{array}{l}\text { Unilateral } \\
\text { V Ctx }\end{array}$ & 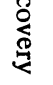 & $\begin{array}{l}\text { Train to } \\
\text { Criterion }\end{array}$ & 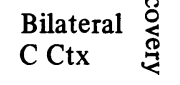 & $\begin{array}{l}\text { Train to } \\
\text { Criterion }\end{array}$ \\
\hline 7 & $\mathrm{NC}+\mathrm{MS}$ & $\begin{array}{l}\text { Train to } \\
\text { Criterion }\end{array}$ & $\begin{array}{l}\text { Bilateral } \\
\text { NC Ctx }\end{array}$ & & $\begin{array}{l}4 \text { Days } \\
\text { Training }\end{array}$ & & $\begin{array}{l}\text { Unilateral } \\
\text { V Ctx }\end{array}$ & & $\begin{array}{l}4 \text { Days } \\
\text { Training }\end{array}$ & $\begin{array}{l}\text { Unilateral } \\
\text { V Ctx }\end{array}$ & $\begin{array}{l}\text { Train to } \\
\text { Criterion }\end{array}$ \\
\hline 8 & $\mathrm{C}+\mathrm{MS}$ & $\begin{array}{l}\text { Train to } \\
\text { Criterion }\end{array}$ & $\begin{array}{l}\text { Bilateral } \\
\text { C Ctx }\end{array}$ & & $\begin{array}{l}4 \text { Days } \\
\text { Training }\end{array}$ & & $\begin{array}{l}\text { Unilateral } \\
\text { V Ctx }\end{array}$ & & $\begin{array}{l}4 \text { Days } \\
\text { Training }\end{array}$ & $\begin{array}{l}\text { Unilateral } \\
\text { V Ctx }\end{array}$ & $\begin{array}{l}\text { Train to } \\
\text { Criterion }\end{array}$ \\
\hline
\end{tabular}

Note-Abbreviations: $S S=$ single stage (lesion of $V C t x), M S=$ multiple stage, $V C t x=$ visual cortex, $C$ Ctx $=$ cortex contiguous with $V C t x, N C C t x=$ cortex noncontiguous with $V C t x$.

*Preoperative "recovery" was introduced to allow dietary repletion prior to surgical trauma.

extensive lesions in all groups did not invade the subcortical areas.

Extensive thalamic retrograde degeneration was found in all animals of each of the experimental groups receiving cortical lesions. Nearly complete degeneration of the dorsal portion of the lateral geniculate nucleus was observed in all animals, thus confirming the impression that the "visual" lesions included most of the striate area and peristriate area. Some sparing was found in a few animals of each of the groups, but it was localized to the dorso-lateral portion of the dorsal lateral geniculate nucleus.

\section{Behavioral}

Preliminary analysis revealed no differences between the unoperated and sham-operated control groups on original training or retrain-1, so these groups were combined as "control" for analysis of the retrain-1 data. Prior to Operation 3, there were no procedural differences among Groups MS $+\mathrm{NC}$ and $\mathrm{MS}+\mathrm{C}$ or among Groups $\mathrm{SS}+\mathrm{NC}$ and $\mathrm{SS}+\mathrm{C}$. Therefore, these groups were combined as Group MS and Group SS, respectively. A 2 (original training vs. retrain-1) by 3 (control vs. MS vs. SS) ANOVA was run on errors to criterion. The main effects for training and groups were significant $(p<.0001)$ as was the Training by Groups interaction $(\mathrm{p}<.0001)$. Group mean errors to criterion on the two tasks are shown in Figure 2. Least squares differences were calculated among the various means. There were no significant differences among original training scores.
Comparison of retrain-1 scores with original training showed significant differences (i.e., "positive savings") for Groups Control and MS but not for Group SS, demonstrating the serial lesion effect. All three groups differed from each other $(p<.01)$ on retrain-1, indicating that though savings were present for Group MS, they were less complete than those of Group Control.

Mean errors to criterion on retrain-2 are shown in Figure 3. For Groups 1-6, performance on the two retrain tasks was compared with a 2 (retrain-1 vs. retrain-2) by 6 (groups) ANOVA. Within-groups comparisons of errors to criterion on retrain-1 and retrain-2 revealed no differences on the two tasks for Groups Unop C, Sham, and MS + NC. Both Groups SS + NC $(p<.01)$ and Group SS +C $(p<.05)$ made fewer errors on retrain- 2 than on retrain-1 and thus showed positive savings on retrain-2. Group $\mathrm{MS}+\mathrm{C}$ showed negative savings on retrain $(\mathrm{p}<.01)$, in marked contrast to Group MS $+\mathrm{NC}$. The savings measures on retrain-2 indicate no differential effect of the additional $\mathrm{C}$ or NC lesion in the SS groups but a dramatic difference between the effects of $\mathrm{C}$ and NC lesions for the MS groups.

Between-group comparisons for all eight groups were made on the last task (retrain-2 for Groups 1-6 and retrain-1 for Groups 7 and 8). The unoperated and sham controls did not differ from each other, but did differ from all other groups $(p<.05)$. Groups SS $+\mathrm{NC}, \mathrm{SS}+\mathrm{C}, \mathrm{MS}+\mathrm{NC}$, and $\mathrm{NC}+\mathrm{MS}$ did not differ from each other. Group $M S+C$ differed from all other groups, as did group C + MS. 
MINIMAL

(a)
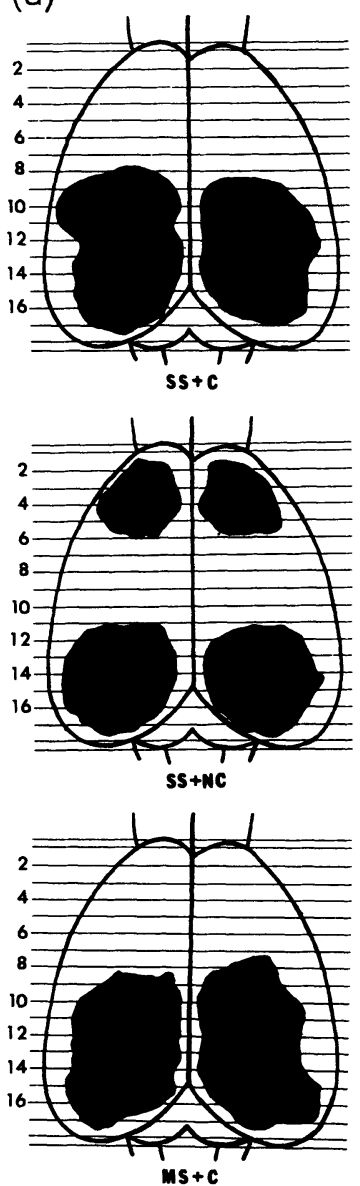

MAXIMAL
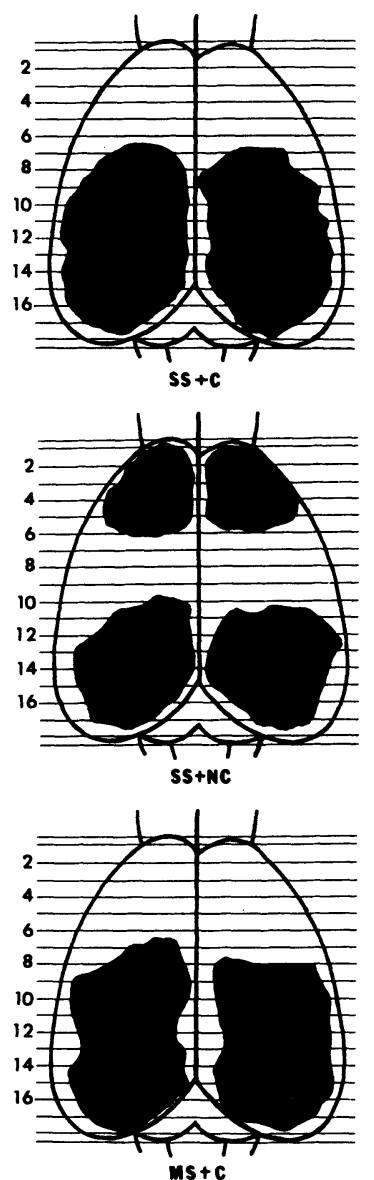

MINIMAL

(b)
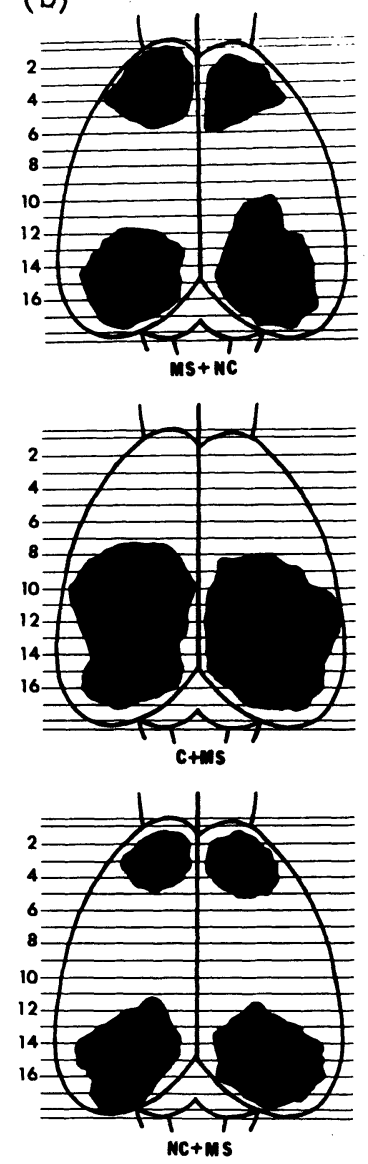

MAXIMAL
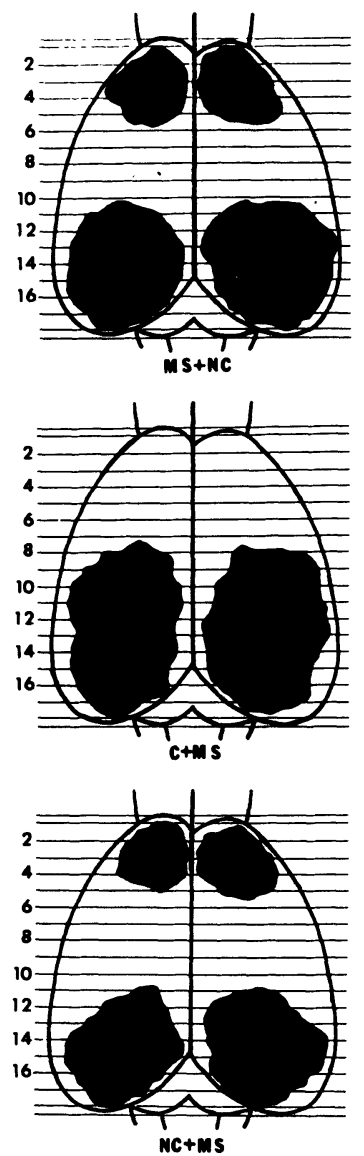

Figure 1. (a) Lashley diagrams representing minimal (left side) and maximal (right side) damage in Groups SS+NC and MS+NC. (b) Lashley diagrams representing minimal (left side) and maximal (right side) damage in Groups MS+C, NC+MS, and C+MS.

\section{DISCUSSION}

The results from the first retraining task demonstrate that the serial lesion effect (positive savings for MS animals, no savings for SS animals) obtains for an appetitive black-white discrimination task. This finding confirms and extends previous demonstrations of the serial lesion effect for shock-escape/ avoidance visual discriminations (Glendenning, 1972; Kircher et al., 1970; Petrinovich \& Bliss, 1966; Petrinovich \& Carew, 1969; Thompson, 1960). The MS animals showed less than complete savings on retrain-1, with more errors to criterion on that task than the control animals. It has been demonstrated that, with lesions of the size used in this study, interoperative training is necessary to the production of the serial lesion effect, both in this task (Scheff \& Wright, 1977) and in the Thompson-Bryant apparatus (Glendenning, 1972; Kircher et al., 1970; Petrinovich \& Carew, 1969; Thompson, 1960). In the present study, the IOI was 9 days with 4 days of training. This IOI may represent, in time and/or training, a lower limit for the production of the serial lesion effect, as is suggested by Finger, Walbran, and Stein (1973).

In this paradigm, the SS comparison groups can receive their bilateral lesion either at the time of Operation 1 ("single-stage early") or at the time of Operation 2 ("single-stage late"). The "early" groups are allowed more recovery time postlesion, while the "late" groups receive some overtraining prior to lesion. A subsequent, procedurally identical study demonstrated that the early and late SS groups did not differ in retraining (Scheff \& Wright, 1977). It is interesting to note that, in that study, multiplestage animals with no interoperative training did not differ from either of the SS groups and are perhaps the best lesion/trauma control group in demonstrations of the serial lesion effect.

On the retrain-2 task, lesions of the contiguous 


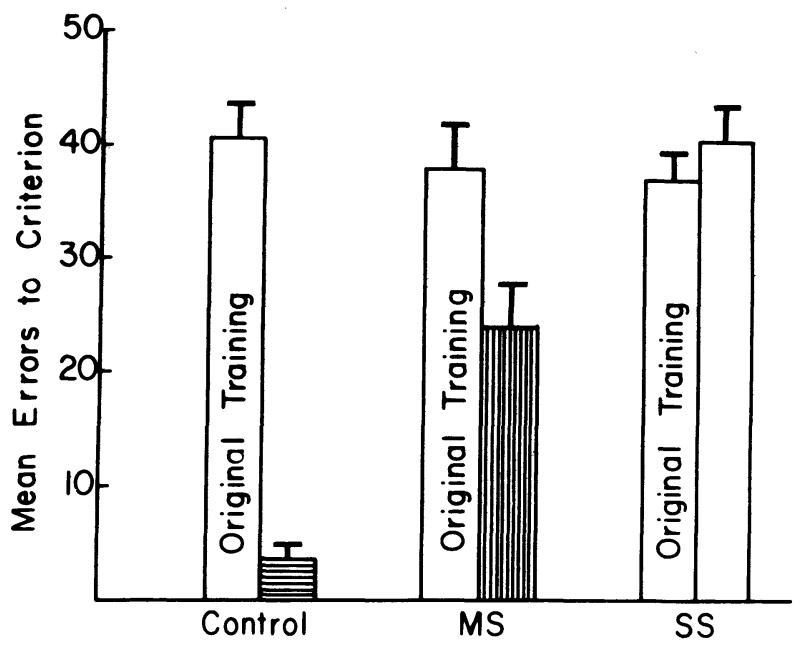

Figure 2. Group mean errors to criterion on original training (left bars) and retrain-1 for the combined groups: "control" (Unop and Cntrls and Sham), "MS" (MS + NC and MS + C), and "SS" (SS + NC and SS +C). Bars with different shadings represent statistically reliable differences $(p<.01)$, bars with same shadings do not differ $(p>.1)$. Vertical lines above the bars represent standard error.

or noncontiguous cortex exerted no differential effects for animals that had undergone SS visual cortex lesions and retraining prior to the $\mathrm{C}$ or $\mathrm{NC}$ lesions. Groups SS $+\mathrm{C}$ and SS $+\mathrm{NC}$ did not differ from each other on retrain-2, and both groups required fewer errors to criterion on retrain-2 than on retrain-1, i.e., both groups showed positive savings on retrain-2. This agrees with Lashley's (1922) findings that rats that are trained following SS visual cortex lesions and then subjected to various lesions of the remaining cortex show substantial savings in retraining.

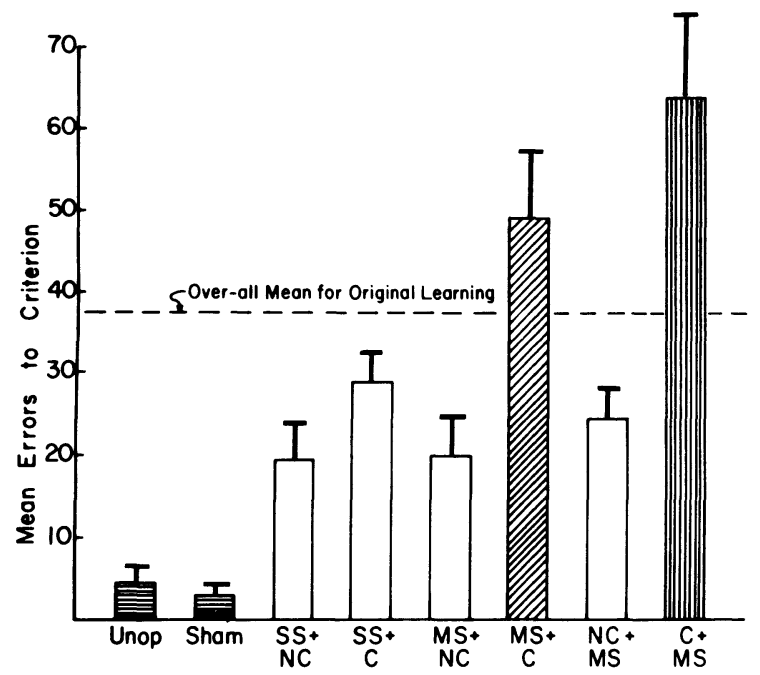

Figure 3. Group mean errors to criterion on the "last task" (retrain-1 for Groups $\mathrm{NC}+\mathrm{MS}$ and $\mathrm{C}+\mathrm{MS}$; retrain-2 for all others). Bars with different shadings represent statistically reliable differences $(p<.05)$, bars with same shadings do not differ $(p>$.1). Vertical lines above the bars represent standard error.
The results for animals given MS visual cortex lesions and retraining prior to $\mathrm{C}$ or $\mathrm{NC}$ lesions are markedly different. Group MS + C made significantly more errors on retrain-2 than did any other group and, while Group MS + NC showed a trend for positive savings on retrain-2, Group MS $+\mathrm{C}$ showed negative savings. Thus, while no differential effect of C or NC lesion is seen in SS animals, the C and NC lesions exert very different effects for MS animals. Moreover, the effects of $\mathrm{C}$ cortex lesion are markedly different for MS and SS animals; Group SS + C showed positive savings on retrain-2, while Group MS $+\mathrm{C}$ showed negative savings on that task.

The analysis of differences among all eight groups on the final task (retrain-2 for Groups 1-6, retrain-1 for Groups 7 and 8) further demonstrates that the effect of $C$ cortex removal is contingent upon the procedures employed for visual cortex removal. Whether C cortex is removed before (Group C+MS) or after $(\mathrm{MS}+\mathrm{C})$ serial lesion of the visual cortex, the effect is the same: marked impairment in retraining on the task. In contrast, animals for whom $\mathrm{C}$ cortex lesion follows simultaneous removal of visual cortex $(\mathrm{SS}+\mathrm{C})$ do not differ from animals given NC lesions after simultaneous visual cortex lesions (SS + NC) or from animals receiving NC cortex lesions either before $(\mathrm{NC}+\mathrm{MS})$ or after $(\mathrm{MS}+\mathrm{NC})$ serial lesions of visual cortex.

NC cortex removal does affect retraining, but this effect is nonspecific in terms of order (i.e., pre or post, $\mathrm{MS}+\mathrm{NC}=\mathrm{NC}+\mathrm{MS}$ ) or procedure for visual cortex removal (i.e., $\mathrm{SS}+\mathrm{NC}=\mathrm{MS}+\mathrm{NC}$ ). The effect of NC cortex removal is perhaps most parsimoniously described as a "mass action" effect.

Interpretations of reorganization/recovery of function following visual cortex lesion typically stress subcortical mechanisms. The differential effects of lesions of contiguous cortex lesion in MS and SS animals coupled with the lack of differential effects for $\mathrm{C}$ or NC lesions among SS animals suggest that, while subcortical mechanisms may be primary for reorganization in SS animals, cortical reorganization of function plays an important role in the savings displayed by MS animals.

It can be argued that following bilateral insult to the visual cortex, rats learn a brightness task on the basis of different or "simpler" cues than do normal animals (Bauer \& Cooper, 1964; Hamilton \& Treichler, 1968 ) and that, if experience with the "simpler" task is given prior to lesion (e.g., with light-diffusing occluders), positive savings in relearning will be shown by SS animals (Cooper et al., 1972).

The positive savings of the MS animal that has interoperative training might be envisioned in two ways. If the animal learns a "complex" task while normal and must relearn the task as "simple" postoperatively, training during the IOI may "ease" the 
transition to the "simpler" task, perhaps by providing "simple" experience while the animal experiences the task as a unilaterally lesioned animal.

On the other hand, the results of Dru et al. (1975) and Spear and Barbas (1975) demonstrate that MS animals with appropriate IOI experience can relearn a "complex" pattern discrimination. If MS animals relearn a brightness discrimination on a "complex" basis, then the positive savings they show for the original "complex" learning is to be expected.

On the basis of the present experiment and the results of Dru et al. (1975) and Spear and Barbas (1975), we would argue that the MS animal does perform a complex discrimination postoperatively and that the reorganization of contiguous cortex plays a critical role in that functional ability. Thus, SS animals show $+\mathbf{2 9 . 8 \%}$ error savings following a subsequent $C$ lesion (Group SS $+C$, retrain-2), while MS animals show $-175.3 \%$ savings following a $C$ lesion (Groups MS $+\mathrm{C}$, retrain-2). Animals whose MS visual lesion is preceded by $C$ lesion show $-86.8 \%$ error savings in retraining (Group C + MS, retrain-1), while MS animals with earlier NC lesion show $+30.8 \%$ error savings (Group NC + MS, retrain-1).

The results of Dru et al. (1975) and a subsequent study with this task (Scheff \& Wright, 1977) further suggest that appropriate experience plays a critical role in initiating the reorganization of $\mathrm{C}$ cortex. It should be noted that it is reasonable to assume, on the basis of the results of Dru et al. (1975) that specific training on the brightness task during the IOI may not be necessary for the serial lesion effect, but rather that specific training is a convenient method for providing integrated visual-motor activity during the IOI.

In short, appropriate IOI experience and the integrity of cortex contiguous with visual cortex appear to be necessary for the behavioral manifestation of the serial lesion effect.

\section{REFERENCES}

BAUER, J. H., \& COOPER, R. M. Effects of posterior cortical lesions on performance of a brightness discrimination task. Journal of Comparative and Physiological Psychology, 1964, 58, 84-92.

Cooper, R. M., Blochert, K. P., Gillespie, L. A., \& Miller, L. C. Translucent occluders and lesions of posterior neocortex in the rat. Physiology and Behavior, 1972, 8, 693-697.

Dru, C., Walker, J. P., \& Walker, J. B. Self produced locomotion restores visual capacity after striate lesions. Science, 1975, 187, 265-266.
Finger, S., Walbran, B., \& Stein, D. G. Brain damage and behavioral recovery: Serial lesion phenomena. Brain Research, 1973, 63, 1-18.

Gellermans, L. W. Chance orders of alternating stimuli in visual discrimination experiments. Journal of Genetic Psychology, 1933, 42, 206-208.

Glendenning, R. L. Effects of training between two unilateral lesions of visual cortex upon ultimate retention of black-white discrimination habits by rats. Journal of Comparative and Physiological Psychology, 1972, 80, 216-229.

Hamilton, D. M., \& TreichleR, F. R. Multiple stimulus dimensions in brightness discrimination learning by rats with striate lesions. Journal of Comparative and Physiological Psychology, 1968, 66, 363-368.

Horel, J. A., Bettinger, L. A., Royce, G. J., \& Meyer, D. R. Role of neocortex in the learning and relearning of two visual habits by the rat. Journal of Comparative and Physiological Psychology, 1966, 61, 66-78.

Kircher, K. A., Braun, J. J., Meyer, D. R., \& Meyer, P. M. Equivalence of simultaneous and successive neocortical ablations in producing impairments of black-white habits in rats. Journal of Comparative and Physiological Psychology, 1970, 71, 420-425.

KRIEG, W. J. S. Connections of the cerebral cortex: I. The albino rat. Journal of Comparative Neurology, 1946, 84, 221-275.

LAshley, K. S. Studies of cerebral function in learning. Psychobiology, 1920, 2, 55-135.

LASHLEY, K. S. Studies of cerebral function in learning. IV. Vicarious function after destruction of the visual areas. American Journal of Physiology, 1922, 59, 44-71.

LASHLEY, K. S. Studies of cerebral function in learning. VII. The relation between cerebral mass, learning and retention. Journal of Comparative Neurology, 1926, 41, 1-58.

LASHLEY, K. S. Brain mechanisms and intelligence. Chicago: University of Chicago Press, 1929.

LASHLEY, K. S. The mechanism of vision. II. The influence of cerebral lesions upon the threshold of discrimination for brightness. Journal of Genetic Psychology, 1930, 37, 461-480.

LASHLEY, K. S. The mechanism of vision. XII. Nervous structures concerned in habits based on reactions to light. Comparative Psychology Monographs, 1935, 11, 43-79.

Petrinovich, L., \& Bliss, D. Retention of a learned brightness discrimination following ablations of the occipital cortex in the rat. Journal of Comparative and Physiological Psychology, 1966, 61, 136-138.

Petrinovich, L., \& Carew, T. J. Interaction of neocortical size and interoperative experience in retention of a learned brightness discrimination. Journal of Comparative and Physiological Psychology, 1969, 69, 451-454.

SChefF, S. W., \& WRIGHT, D. C. Behavioral and electrophysiological evidence for cortical reorganization of function in rats with serial lesions of the visual cortex. Physiological Psychology, 1977, 5, 103-107.

SPEAR, P. D., \& Barbas, H. Recovery of pattern discrimination ability in rats receiving serial or on stage visual cortex lesions. Brain Research, 1975, 94, 337-346.

Tномpson, R. Retention of a brightness discrimination following neocortical damage in the rat. Journal of Comparative and Physiological Psychology, 1960, 53, 212-215.

(Received for publication June 25, 1976; revision accepted November 16, 1976.) 